\title{
Lightning generated electric field over land and sea at Northern Region of Peninsular Malaysia: Measuring Setup
}

\author{
Ahmad Muhyiddin Yusof ${ }^{1,2}$, Zulkurnain Abdul-Malek ${ }^{1}$, Chin-Leong Wooi ${ }^{2}$ \\ ${ }^{1}$ Institute of High Voltage and High Current, School of Electrical Engineering, Faculty of Engineering, \\ Universiti Teknologi Malaysia, Johor Bahru, Malaysia \\ ${ }^{2}$ Centre of Excellence for Renewable Energy, Faculty of Electrical Engineering Technology, Universiti Malaysia Perlis \\ (UniMAP), Perlis, Malaysia
}

\begin{abstract}
Article Info
Article history:

Received May 1, 2020

Revised Sep 10, 2020

Accepted Oct 1, 2020

Keyword:

Broadband antenna

Electromagnetic measurement

Lightning discharge

HF radiation

Denoising

ABSTRACT

Lightning electric fields can be characterized based on its origins which include the preliminary breakdown, stepped leader, return stroke, subsequent return stroke, dart leader, dart-stepped leader, narrow bipolar pulses, cloud activity between strokes, regular pulse trains, $\mathrm{K}$ and $\mathrm{M}$ changes, and chaotic pulse trains. The aim of this work is to describe a lightning measuring setup suitable for characterizing lightning electric fields and their propagation when the measuring sensors are close to the sea. A location close to the sea in Northern Malaysia was identified and prepared for the study. Parallel plate and vertical whip antennas are used as the main sensors, which are connected to a high-speed digital storage oscilloscope through customized analog filter buffer circuits. Noise-distortion effects in the recorded data are filtered using MATLAB computer simulation before further analyses are carried out. The 1-D wavelet technique is used in the signal denoising process. Preliminary results show that the installed setup and denoising method is adequate and potentially efficient for the pre-processing of lightning electric field signals, and hence can be used for the detailed characterization study including the effects of sea on lightning characteristics and propagation.
\end{abstract}

Copyright (C) 2020 Institute of Advanced Engineering and Science. All rights reserved.

\section{Corresponding Author:}

Zulkurnain Abdul-Malek, Institute of High Voltage and High Current (IVAT),

Universiti Teknologi Malaysia,

Johor Bahru, 81310, Johor, Malaysia

Email: zulkurnain@utm.my

\section{INTRODUCTION}

Lightning is the transfer of significant charge between two charged objects, it can appear between cloud-to-cloud, cloud-to-air and cloud-to-ground. Lightning flashes produce wide-band electromagnetic pulses ranging from few $\mathrm{Hz}$ to several $\mathrm{GHz}$ [1]. A lightning discharge generates an electrical field in space which can usually be classified as vertical and horizontal components. The advancement of lightning measurement and technology in continuous growth leads to several well-known techniques such as satellite imaging systems [2-3], high speed photography [4-8], interferometric method [9], and lightning locating systems [10-14]. The study of electric fields produced by lightning, especially on lightning characterization was seen as one of the most important discoveries for electrical engineers and researchers.

A number of researchers presented new findings on lightning event characteristics via electrical field sensors [15-19]. All lightning activities are correlated with charge movement and therefore, it can be studied using measurement of electrostatic field (slow field changes), radiation field (fast field changes) and magnetic field affiliated with charge movement. This measurement setup is often used to perform electric field characterization related to different lightning events such as preliminary breakdown, stepped leader, return stroke, subsequent return stroke, dart leader, dart-stepped leader, narrow bipolar pulses and cloud activity between strokes, such as regular pulse trains, $\mathrm{K}$ and $\mathrm{M}$ changes and chaotic pulse trains. 
When obtaining a particular lightning generated electrical field component, the use of an appropriate electrical field measuring system is absolutely essential. A suitable antenna such as a parallel flat-plate antenna can be used to measure the vertical component of the electric field [20]. Changes in the atmospheric electric field intensity cause a corresponding change between the top metallic plate of the antenna and the ground for both the lengthy vertical-whip antenna pole and the parallel flat-plate antenna configuration. In order to avoid any interference of the horizontal electric field, the parallel plate antennas were placed 90 degrees to the electric field vector, or parallel to the ground. Using a vertical-whip antenna and a parallel plate antenna, the measurement of the electrostatic field (also known as the slow electric field), the broadband radiation field (also known as the fast electric field), the field time derivatives (dE/dt), and the narrowband radiation field (using the so-called $3 \mathrm{MHz} \mathrm{HF}$ antenna) becomes possible [21]. The fast electric field waveform is valuable because it has excellent reliability in demonstrating a consistent segment of different lightning occurrences, such as cloud to ground (CG), intracloud (IC) and narrow bipolar pulses (NBP). In order to better define the starting point of electric field changes caused by the preliminary breakdown, the slow electric field waveform is also needed. This starting position was appropriately being suggested as a beginning of negative charge movement towards ground [22]. On the other hand, K-change events can be well-defined by using slow electric field measurement [23]. First indication of preliminary breakdown pulse can be identified using a narrowband system method ( $3 \mathrm{MHz}$ ) [21]. Furthermore, the time derivatives $(\mathrm{dE} / \mathrm{dt})$ can indicate the lightning flashes are probably produced by different physical processes, such as physical mechanisms of initial breakdown pulses and narrow bipolar by comparing and contrasting the electric field derivatives with the electric field [16]. With all this measurement system, the characterization of the lightning flash can be done thoroughly and correctly.

Lightning measurements are characterized by an appreciable degree of noise. Measuring systems can be disturbed by unwanted phenomena, such as any external event affecting the measured phenomenon and electronic noise. This actually depends on what is measured and on the sensitivity of the measuring system. Previous studies [24-26] suggest that it is possible to enhance the lightning electric field measurements by means of wavelet based denoising techniques.

To enhance our comprehension of the lightning mechanism, acquiring information about the lightning discharge and its related events is essential. Research on lightning in Malaysia had been previously carried out by several researchers [27-29]. However, in Peninsular Malaysia the availability of research on lightning characterization pertinent to the sea is still scarce and not thoroughly studied. A comprehensive statistical data of lightning at sea, particularly in the northern region of Malaysia, is still unavailable to date. In addition, a measuring station located close to the sea may give new information on the propagation effects of the lightning discharge over sea and land.

\section{METHODOLOGY}

\subsection{Hardware implementation of electric field measurement system}

Fast-electric field, $3 \mathrm{MHz}$ radiation fields and electric field time derivative (dE/dt) were obtained by three separate parallel-plate antennas, while a slow electric field signal was observed using a vertical whip antenna. A parallel-plate antenna usually has two horizontal discs, the top plate being an active plate and the other grounded. Every parallel-plate antenna has an insulator thickness, physical height and diameter of approximately $0.05,1.5$ and $0.47 \mathrm{~m}$ respectively. As in Figure 1, all three of these antennas were mounted next to each other, 2 metres apart. The vertical-whip antenna was identified with a lower metal rod, upper metal $\operatorname{rod}(3.3 \mathrm{~m})$, and an insulator (separating lower and top rod). The lower metallic was 2 metres above ground level. A $0.05 \mathrm{~m}$ thick insulator (nylon) was used to insulate the top and bottom metal rods. The antenna was perpendicular to the parallel flat-plate antenna, 2 metres apart.

The antennas are positioned 10 metres away from the control room where the recording devices are assembled. Signals from all antennas were transmitted to a 4-channel digital transient recorder (HDO 4240 Lecroy) via $10 \mathrm{~m}$ long coaxial cables (RG-58). Long coaxial cables need a matching resistor at the oscilloscope input to avoid unwanted reflection. The sampling rate was set at $12.5 \mathrm{MSample} / \mathrm{s}$ with a recording time of 1 second. The oscilloscope was set to window trigger mode at a $500 \mathrm{mV}$ threshold level and a $150 \mathrm{~ms}$ pre-trigger time to ensure that cloud-to-ground lightning was recorded accordingly. The trigger setting was set such as that to enable both polarity signals (positive and negative cloud to ground) are being captured. The oscilloscopes were set to operate automatically, which will be triggered on any signal reaching a preset trigger level, store a captured signal in the external hard disc and send a pulse to the GPS device for a timestamp of the relevant lightning activity. The GPS is synchronized to UTC time with nanosecond precision. The Tenaga Nasional Berhad Research's data are then matched with GPS time to get the ground flash approximated locations. While the data are being recorded and processed, this inevitably results in a several second dead time before the next trigger can be executed. The broadband electric field (Fast field) is 
the key source of signal triggering. As the oscilloscope triggered, it simultaneously sent a signal to the narrowband device, meaning each broadband record matches a narrowband record.

A buffer circuit architecture for slow, fast and time derivatives consists of a buffer amplifier (MSK0033), resistors and capacitors [30]. Meanwhile, the $3 \mathrm{MHz}$ tuning circuit is an integration of passive elements where the inductance $(47 \mu \mathrm{H})$ is connected to the antenna $(58 \mathrm{pF})$ and $50 \Omega$ termination in series forming a simple RLC circuit [30]. The field derivative measuring circuit was created based on the fast electric field. However, a T-junction with a $50 \Omega$ parallel resistor was added (between the antenna and circuit) [31]. All circuits associated with fast, slow, $3 \mathrm{MHz}$ and time derivatives of electric field are enclosed with aluminium cases and mounted under each parallel-plate antenna in a weatherproof box as shown in Figures 3 and 1, respectively. The parallel-plate antenna is connected to the circuits via short coaxial cable RG58 (1.6 m). A $\pm 12 \mathrm{Vdc}$ voltage source supplied the rest of the circuit, except for the $3 \mathrm{MHz}$. The detailed description of the antenna design, electronic buffer circuits and the measuring device calibration can be found in $[21,30-32]$.

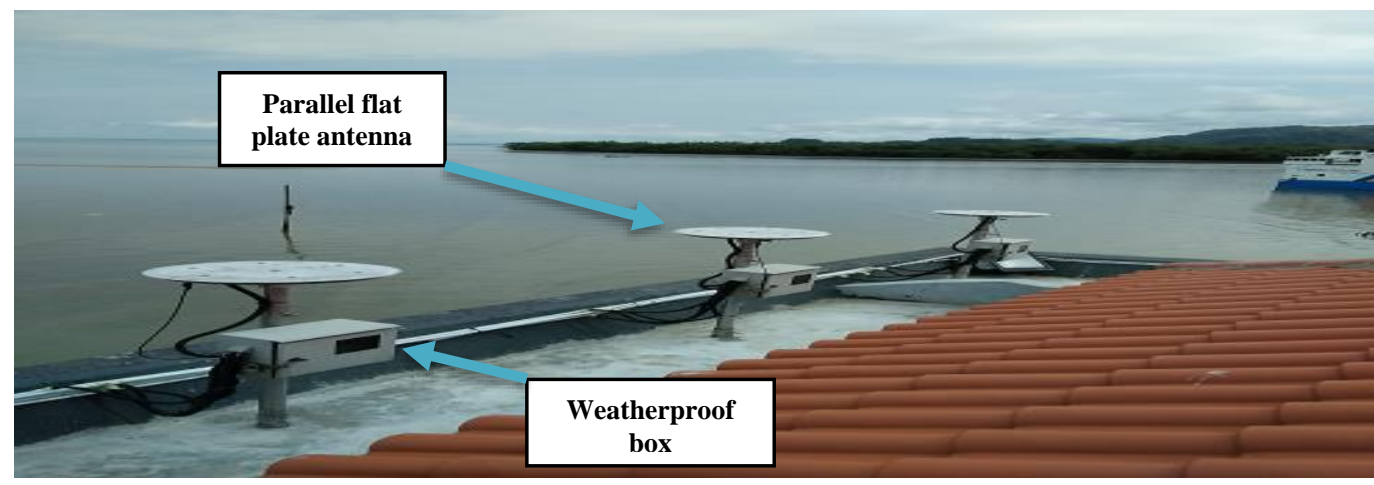

Figure 1. Three parallel flat plate antennas with weatherproof boxes

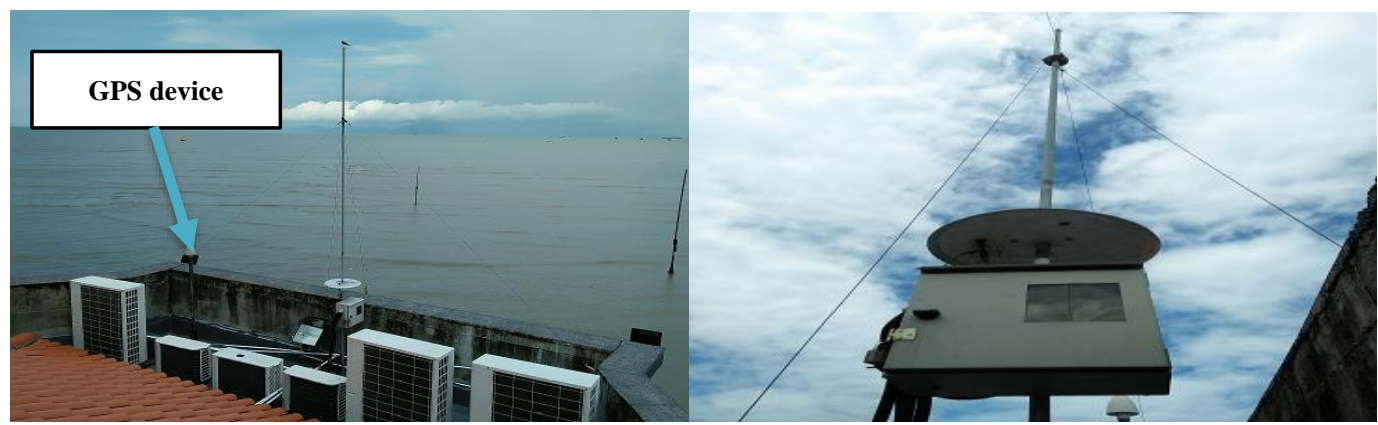

Figure 2. Vertical Whip antenna (next to antenna was a GPS device)

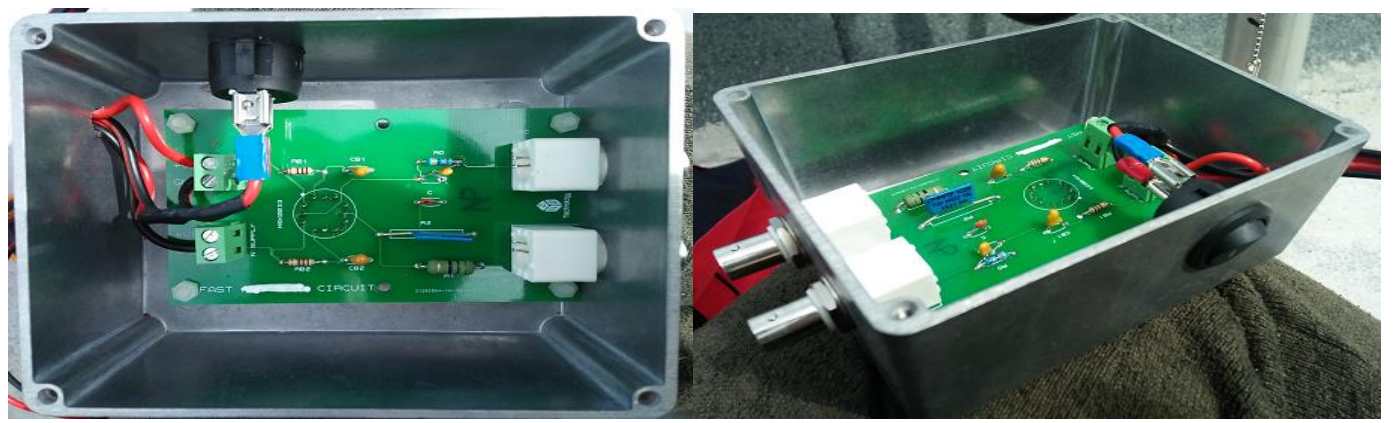

Figure 3. Circuit enclosure (Aluminium box)

The electrical field produced by lightning flash at any time is the accumulation of static, induction and radiation contributions. It is noted that the magnitude and shape lightning electrical field captured in a sensor is dependent on the location of the sensor from the lightning strike point. The static electric field is dominant at near distance (within $5 \mathrm{~km}$ ), then at medium distance (approximately $5-10 \mathrm{~km}$ ) the induction electric field is more dominant and the radiation field is dominant at large distance (more than $10 \mathrm{~km}$ ) [33]. As reported [47] within the reversal distance (typically $\leq 7 \mathrm{~km}$ ), a fast field system recorded radiation and electrostatic components of the lightning-emitted electric field, while the slow field system primarily recorded 
electrostatic and inductive components of the electric field. A slow electric field antenna is used to replicate field changes from a complete lightning discharge. This includes not only changes in the return stroke, but also leader processes and continuing currents that may occur between return strokes. The fast-electric field antenna measures portions of the lightning discharge on a faster time scale. The RC constant in the fast antenna is small, so most of the static field is removed from the device output compared to the RC constant in the slow antenna which faithfully captures the changing static field [30,32].

\subsection{Measurement station}

This research was performed in Kuala Perlis, Malaysia $\left(6.3979^{\circ} \mathrm{N}, 100.1307^{\circ} \mathrm{E}\right)$ on the northern coast of Peninsular Malaysia. An electric field antenna was located on a Kuala Perlis Mosque roof as shown in Figure 4(a) at an altitude of 10 meters above sea level and less than $50 \mathrm{~m}$ from Kuala Perlis beach, Malacca Straits Ocean, as shown in Google Maps in Figure 4(b). The control room where recording device was mounted was 4 metres below antenna position. It is evident in Figure $4 \mathrm{a}$ that the location of the antennas is below the height of the dome, but this does not mean that it might cause any disturbance to the lightning calculation in the form of wave reflection or anything similar. The height of the dome is critical in order to provide a robust protection zone for the mosque and the surrounding area, along with the lightning rod as a point where the lightning hits the structure and then transfers the current safely to the ground [45-46]. Again, the dome (embedded with a lightning rod at the centre) provides lightning protection for both the mosque and the antennas, while the lightning antennas are used to measure the electrical field propagating to the measuring station $[16,48]$.

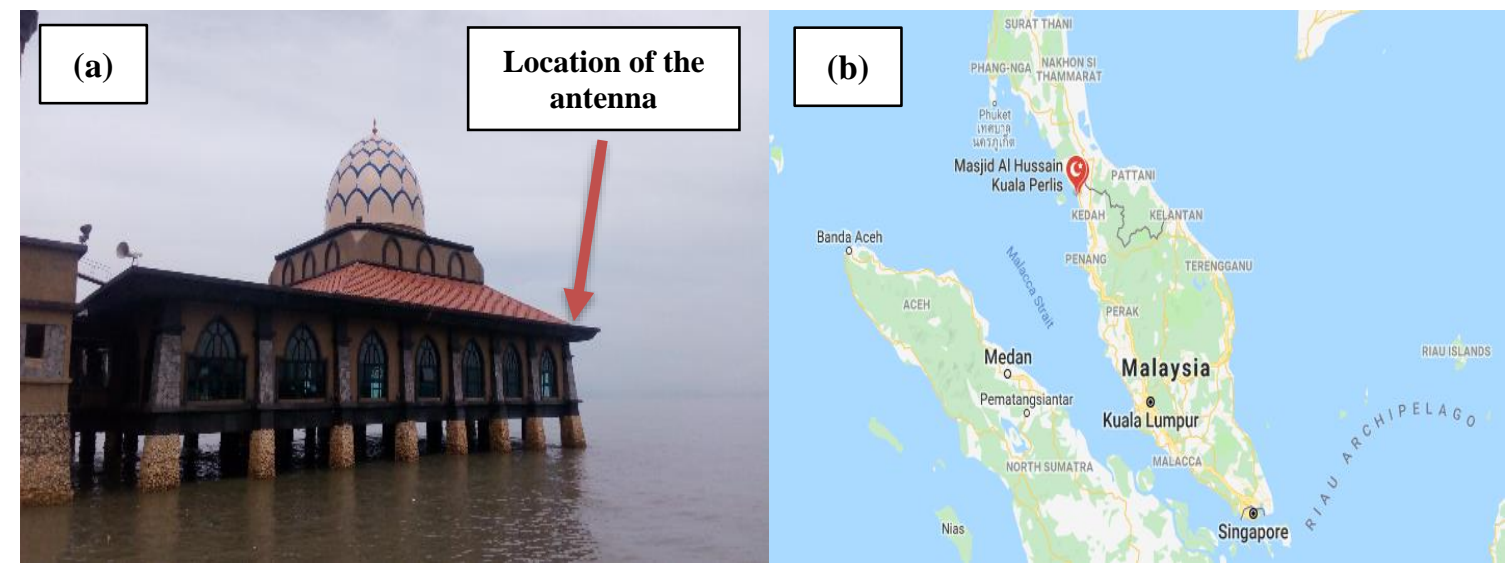

Figure 4. (a) Side view of Al Hussain mosque Kuala Perlis and (b) Al Hussain mosque on Google Maps

\subsection{Wavelet based denoising techniques}

Being a relative recent concept, the wavelet transform is being increasingly used in problems of pattern recognition, in processing and synthesizing various signals, in analysis of images of any kind, for study of turbulent fields, for compression of large volumes of information, in denoising of several types of signals, and in many other cases [24]. Moreover, the wavelet transform (WT), unlike Fourier transform (FT), provides a local representation in both time and frequency of a given signal, therefore, it is suitable for analyzing a signal where time-frequency resolution is needed, such as in lightning electric field measurements. In past decades, many researchers have made an attempt to use signal analyses in time and frequency domains to distinguish distinct types of lightning discharges [34-38]. Because of its advantages, WT was employed in this research to eliminate noise from measured data as efficiently as possible while preserving the critical characteristics of the lightning electric field signal.

Denoising wavelet decomposition signals allows separating signal from noise by iterative filtering using a filter bank. A digital filter is described based on a couple of fundamental features including mother wavelet function and scaling function. Depending on the type of feature chosen, the decomposition results can vary in large range even for the same signal. The output of the filter is separated into the detailed coefficients and the approximated coefficients. The former applies to the high-pass filter output, while the latter applies to the low-pass filter output. Information coefficients are typically correlated with the noise element and can also include details of the real signal [26]. However, it is important to highlight which sections of these coefficients will remain in the signal. Detailed wavelet theory goes beyond the scope of this work. A detailed treatment of how it operates theoretically can be found in [39-44]. Figure 5 shows the wavelet transformation technique implemented in this work, as also described in [24-25]. 


\section{RESULTS AND ANALYSIS}

The following results were performed using Wavelet 1-D denoising tools in MATLAB software. Figure 6 shows a simultaneous electric field of negative cloud-to-ground lightning flash recorded at 6:15 pm, 8 May 2019. Obvious presence of noise in $3 \mathrm{MHz}$ and fast field derivative waveform suggests high noise content (thicker ripples and oscillations) compared to the other two less noise waveforms. Such noise-induced oscillations gave rise to interpretational difficulties. In the case of wavelet-based denoising, the method presented in Figure 5 was applied, four electric field waveforms above-mentioned were processed manually on a trial and error basis by visual inspection until a finer result was acquired. In this way, wavelet Symmlet (8) with 5-level decomposition and fixed from threshold (hard) with non-white noise thresholding is the optimal selection for denoising. However, this denoising selection is unlikely the same when executing with other recorded lightning flashes due to noise level in the signal. Moreover, it is vital to recognize the exact signatures of the lightning flashes prior noise elimination, in order to preserve the signal of interest.

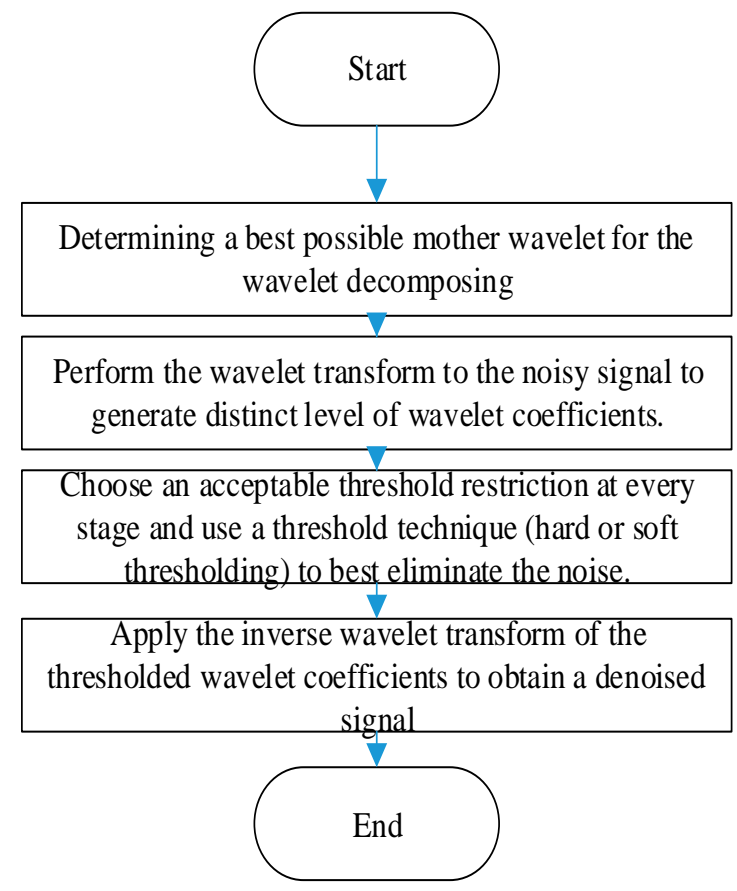

Figure 5. An overview of Wavelet denoising

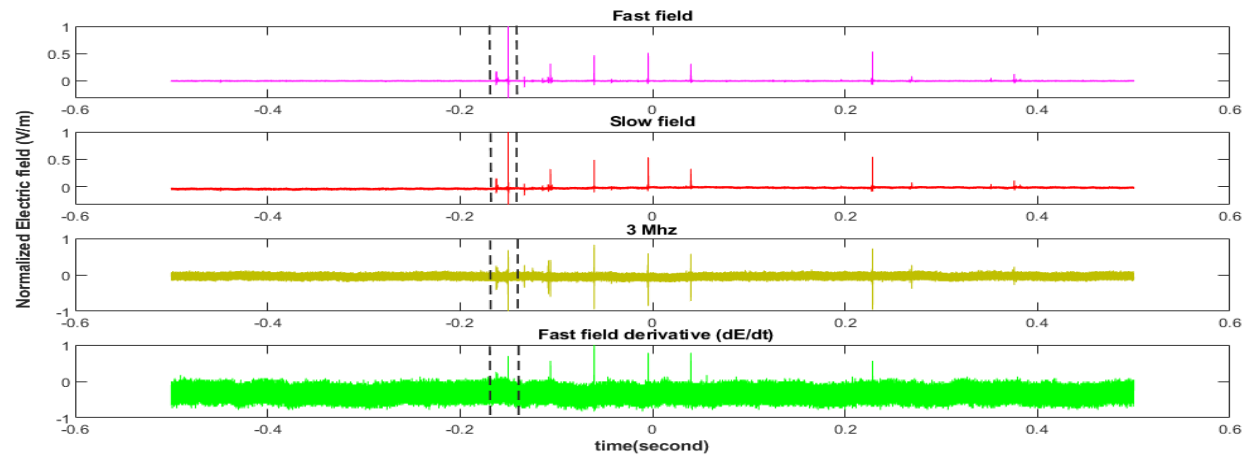

Figure 6. One second record of the whole flash (a) Fast field, (b) Slow field, (c) $3 \mathrm{MHz}$ and (d) Fast field derivative

Figure 7 depicts the denoised signals of four negative cloud-to-ground (-CG) electric field waveforms. All waveforms were magnified (as in segmented-line zone), highlighted on preliminary breakdown and first return stroke. Significantly, a smooth view of the preliminary breakdown (B), intermediate (I), and stepped leader (L) type, obviously improving visualization with less noise in the lightning flash waveform. These figures show how signal processing using wavelet-transform facilitates the generation of denoised electrical field signals without filtering out sharp structures of physical meaning, leading to a trimmed-up signal that still presents significant details. 


\section{CONCLUSION}

This work has successfully designed, constructed and installed a suitable lightning measuring system to be used to study the sea effects on lightning and its propagation. The parallel flat-plate and verticalwhip antennas were successfully used to detect the vertical component of lightning electric field signals during the thunderstorm days. The lightning electric field generated pertinent to the northern region of peninsular Malaysia over land and sea was recorded simultaneously using fast field, slow field, time derivative $(\mathrm{dE} / \mathrm{dt})$, and narrow field $(3 \mathrm{MHz})$ antenna systems. The effects of noise distortion on the captured lightning electric field signals were successfully solved using Wavelet-based denoising method with automatic level thresholding. The measuring setup and the denoising method is shown to be adequate and potentially efficient for further lightning characterization and propagation effects studies.

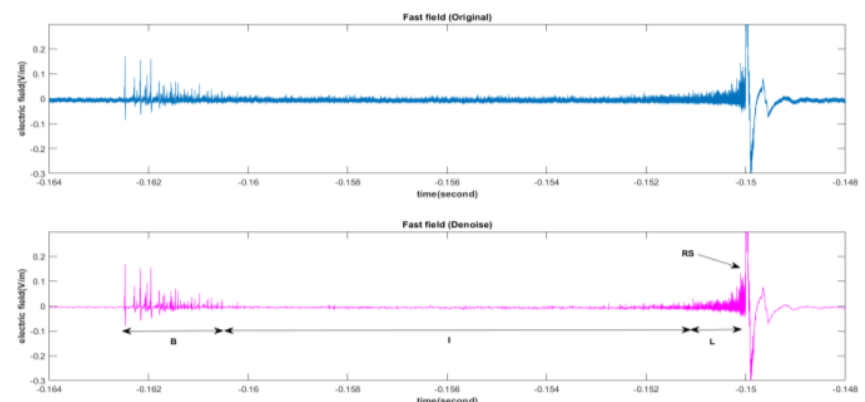

(a)
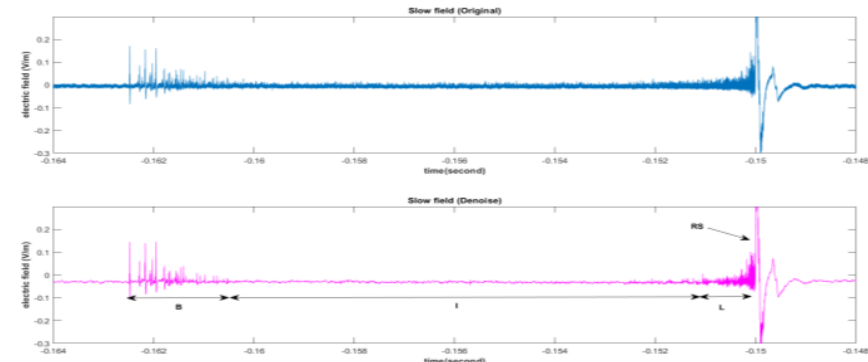

(b)

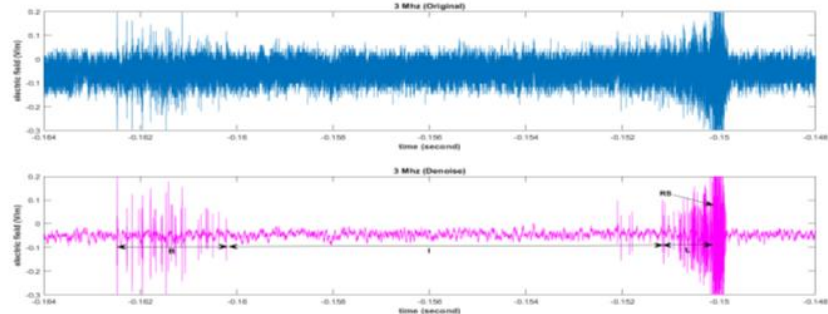

(c)

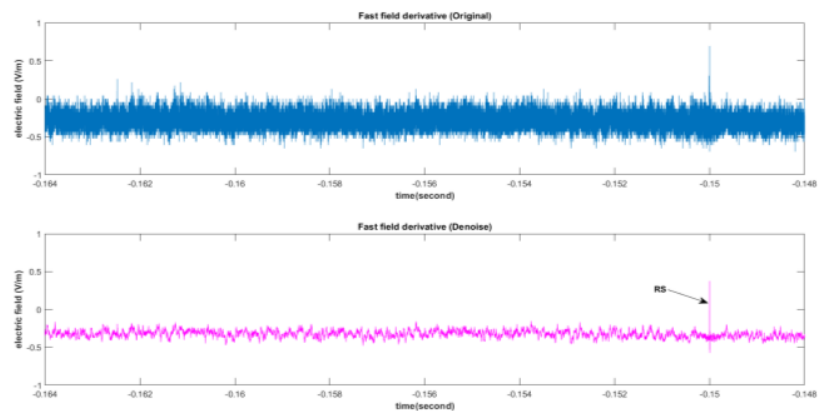

(d)

Figure 7. (a) Fast field - original and denoised signal of negative CG with a BIL form , (b) Slow field original and denoised signal of negative CG with a BIL form, (c) $3 \mathrm{MHz}$ - original and denoised signal of negative CG with a BIL form, (d) Fast field derivative - original and denoised signal of negative CG 


\section{ACKNOWLEDGEMENTS}

Authors wish to thank Universiti Malaysia Perlis (4B482), Universiti Teknologi Malaysia (01M44, 02M18 \& 05G88) and Universitas Sriwijaya (4B379) for the financial support.

\section{REFERENCES}

[1] F. Diaz-Ortiz, F. Roman, J. Lopez, and C. Gomez, "High-speed data acquisition system for radio atmospheric signals measurements based on software defined radio," 2016 33rd Int. Conf. Light. Prot. ICLP 2016, no. September, 2016.

[2] R. J. Thomas et al., "Comparison of ground-based 3-dimensional lightning mapping observations with satellitebased LIS observations in Oklahoma," Geophys. Res. Lett., vol. 27, no. 12, pp. 1703-1706, 2000.

[3] A. R. Jacobson and X. M. Shao, "FORTE satellite observations of very narrow radiofrequency pulses associated with the initiation of negative cloud-to-ground lightning strokes," J. Geophys. Res. Atmos., vol. 107, no. 22, 2002.

[4] S. P. A. Vayanganie, M. Fernando, U. Sonnadara, V. Cooray, and C. Perera, "Optical observations of electrical activity in cloud discharges," J. Atmos. Solar-Terrestrial Phys., vol. 172, no. February 2017, pp. 24-32, 2018.

[5] M. G. Andreev, M. U. Bulatov, A. Y. Kostinsky, L. M. Makalsky, D. I. Sukharevsky, and V. S. Syssoev, "Return stroke initiated by the contact between a downward negative leader from the aerosol cloud and upward positive leader from the grounded plane," 15th Int. Conf. Atmos. Electr. (ICAE 2014), no. June, p. P-03-07, 2014.

[6] V. A. Rakov et al., "High-Speed Optical Imaging of Lightning and Sparks: Some Recent Results," IEEJ Trans. Power Energy, vol. 138, no. 5, pp. 321-326, 2018.

[7] C. P. Barrington-Leigh, U. S. Inan, and M. Stanley, "Identification of sprites and elves with intensified video and broadband array photometry," J. Geophys. Res. Sp. Phys., vol. 106, no. A2, pp. 1741-1750, Feb. 2004.

[8] M. M. F. Saba, M. G. Ballarotti, and J. Pinto, "Negative cloud-to-ground lightning properties from high-speed video observations," J. Geophys. Res. Atmos., vol. 111, no. 3, p. D03101, 2006.

[9] F. Lyu, S. A. Cummer, G. Lu, X. Zhou, and J. Weinert, "Imaging lightning intracloud initial stepped leaders by low-frequency interferometric lightning mapping array," Geophys. Res. Lett., vol. 43, no. 10, pp. 5516-5523, May 2016.

[10] P. M. Bitzer and J. C. Burchfield, "Bayesian techniques to analyze and merge lightning locating system data," Geophys. Res. Lett., vol. 43, no. 24, pp. 12,605-12,613, Dec. 2016.

[11] A. Mohd, "Lightning Locating Using Interferometry Technique," Master Thesis, 2012.

[12] S. V. Mashak, H. N. Afrouzi, and Z. Abdul-Malek, "Simulation of lightning flash in Time of Arrival (TOA) method by using three broadband antennas," Proc. - UKSim 5th Eur. Model. Symp. Comput. Model. Simulation, EMS 2011, pp. 287-292, 2011.

[13] A. Nag, M. J. Murphy, W. Schulz, and K. L. Cummins, "Lightning locating systems: Insights on characteristics and validation techniques," Earth and Space Science, vol. 2, no. 4. Wiley-Blackwell Publishing Ltd, pp. 65-93, 2015.

[14] Z. Abdul-malek and Z. Adzis, “A New Localised Lightning Locating System - Software Implementation,” 2008 Australas. Univ. Power Eng. Conf., pp. 1-5, 2008.

[15] S. Nanayakkara, M. Fernando, and V. Cooray, "Features of K-Changes Observed in Sri Lanka in the Tropics," Atmosphere (Basel)., vol. 10, no. 3, p. 141, 2019.

[16] M. Muzafar Ismail, "Features and Origin of Electromagnetic Fields Generated by Lightning Flashes," $P H D$ Thesis, vol. 54, pp. 1-56, 2017.

[17] D. Johari, V. Cooray, M. Rahman, P. Hettiarachchi, and M. M. Ismail, "Features of the first and the subsequent return strokes in positive ground flashes based on electric field measurements," Electr. Power Syst. Res., vol. 150, pp. 55-62, 2017.

[18] H. Rojas, A. Cruz, and C. Cortés, "Characteristics of lightning-generated electric fields measured in the Bogotá Savanna, Colombia," Rev. UIS Ing., vol. 16, no. 2, pp. 243-252, 2018.

[19] D. Johari, V. Cooray, M. Rahman, P. Hettiarachchi, and M. M. Ismail, "Characteristics of preliminary breakdown pulses in positive ground flashes during summer thunderstorms in Sweden," Atmosphere (Basel)., vol. 7 , no. 3, p. 39, 2016.

[20] K. Mehranzamir, M. Davarpanah, Z. Abdul-Malek, and H. N. Afrouzi, "Discriminating cloud to ground lightning flashes based on wavelet analysis of electric field signals," J. Atmos. Solar-Terrestrial Phys., vol. 181, no. February, pp. 127-140, 2018.

[21] Z. A. Baharudin, "Characterizations of ground flashes from tropic to northern region," PHD Thesis, pp. 1-80, 2014.

[22] Z. A. Baharudin, M. Fernando, N. A. Ahmad, J. S. Mäkelä, M. Rahman, and V. Cooray, "Electric field changes generated by the preliminary breakdown for the negative cloud-to-ground lightning flashes in Malaysia and Sweden," J. Atmos. Solar-Terrestrial Phys., vol. 84-85, pp. 15-24, 2012.

[23] S. Nanayakkara, M. Fernando, and V. Cooray, "Features of K-changes observed in Sri Lanka in the tropics," Atmosphere (Basel)., vol. 10, no. 3, 2019.

[24] F. Santamaría, C. A. Cortés, and F. Roman, "Noise reduction of measured lightning electric fields signals using the wavelet transform," X Int. Symp. Light. Prot., p. 6, 2009.

[25] C. Cortes, F. Santamaria, F. Roman, F. Rachidi, and C. Gomes, "Analysis of wavelet based denoising methods 
applied to measured lightning electric fields," 2010 30th Int. Conf. Light. Prot., pp. 1-6, 2010.

[26] F. Diaz-Ortiz and F. Roman, "Wavelet denoising using an optimal selection of mother wavelet for compact intracloud discharges," 2018 34th Int. Conf. Light. Prot., pp. 1-4, 2018.

[27] C. L. Wooi, Z. Abdul-Malek, N. A. Ahmad, M. Mokhtari, and B. Salimi, "Statistical analysis on preliminary breakdown pulses of positive cloud-to-ground lightning in Malaysia," Int. J. Electr. Comput. Eng., vol. 6, no. 2, pp. 844-850, 2016.

[28] B. Salimi, K. Mehranzamir, and Z. Abdul-Malek, "Statistical analysis of lightning electric field measured under malaysian condition," Asia-Pacific J. Atmos. Sci., vol. 50, no. 2, pp. 133-137, 2014.

[29] Z. A. Baharudin, N. A. Ahmad, J. S. Mäkelä, M. Fernando, and V. Cooray, "Negative cloud-to-ground lightning flashes in Malaysia," J. Atmos. Solar-Terrestrial Phys., vol. 108, pp. 61-67, 2014.

[30] N. Ahmad, "Broadband and HF radiation from cloud flashes and narrow bipolar pulses," PHD Thesis, 2011.

[31] C. Wooi, "Temporal and Spectral Features of Lightning Generated Vertical Electric Fields Observed in Malaysia," PHD Thesis, pp. 1-221, 2017.

[32] A. Galvan and M. Fernando, "Operative characteristics of a parallel-plate antenna to measure vertical electric fields from lightning flashes," 2000.

[33] V. Cooray, An Introduction to Lightning. 2017.

[34] C. L. Wooi, Z. Abdul-Malek, N. A. Ahmad, M. R. M. Esa, Z. Zakaria, and M. R. Ahmad, "Wavelet analysis of chaotic pulse trains prior to subsequent return strokes in Malaysia," 2016 33rd Int. Conf. Light. Prot., pp. 1-6, 2016.

[35] M. R. M. Esa, "Temporal and Wavelet Characteristics of Initial Breakdown and Narrow Bipolar Pulses of Lightning Flashes," PHD Thesis, p. 52, 2014.

[36] F. J. Miranda, "Wavelet analysis of lightning return stroke," J. Atmos. Solar-Terrestrial Phys., vol. 70, no. 1112, pp. 1401-1407, 2008.

[37] B. Salimi, "Time Difference of Arrival-based Three-station Lighting Locating System in Malaysia," PHD Thesis, pp. 1-227, 2015.

[38] Y. Chen, "Wavelet analysis and statistics of CN tower lightning current waveforms," Master Thesis, pp. 1-109, 1997.

[39] R. Hong, S. Qiu, and L. Shi, "A wavelet packet based method for detecting lightning leaders in dE/dt signatures," Proc. - 7th Asia-Pacific Conf. Environ. Electromagn. CEEM 2015, pp. 436-439, 2015.

[40] Q. Li, K. Li, and X. Chen, "Research on lightning electromagnetic fields associated with first and subsequent return strokes based on Laplace wavelet," J. Atmos. Solar-Terrestrial Phys., vol. 93, no. 3, pp. 1-10, 2013.

[41] X. Ma, C. Zhou, and I. J. Kemp, “Automated wavelet selection and thresholding for PD detection,” IEEE Electr. Insul. Mag., vol. 18, no. 2, pp. 37-47, 2002.

[42] X. Ma, "Investigation into the use of wavelet theory for partial discharge pulse extraction in electrically noisy environments," vol. 4, pp. 123-126, 2005.

[43] J. Ramirez-Niño, S. Rivera-Castañeda, V. R. Garcia-Colon, and V. M. Castaño, “Analysis of partial electrical discharges in insulating materials through the wavelet transform," Comput. Mater. Sci., vol. 9, no. 3-4, pp. 379388, 2002.

[44] F. Diaz-Ortiz and F. Roman, "Wavelet denoising using an optimal selection of mother wavelet for compact intracloud discharges," 34th Int. Conf. Light. Prot. ICLP 2018, 2018.

[45] Y. P. Bazelyan, Eduard M and Raizer, Lightning Physics and Lightning Protection. 2000.

[46] V. Cooray, Lightning Protection. 2009.

[47] D. Periannan et al., "Performance Analysis of Flame Retardant 4 Copper Plate Antenna for Lightning Remote Sensing," IOP Conf. Ser. Earth Environ. Sci., vol. 228, no. 1, 2019.

[48] K. P. Naccarato, M. M. F. Saba, C. Schumann, O. Pinto, C. Medeiros, and S. Heckman, "Waveform analysis of cloud-to-ground flashes as detected by fast e-field antennas and lightning location systems: On the way to precisely estimate the stroke peak current,” 2013 Int. Symp. Light. Prot. SIPDA 2013, pp. 57-61, 2013. 